\title{
ETHzürich
}

ETH Library

Flow chemistry and polymersupported pseudoenantiomeric acylating agents enable parallel kinetic resolution of chiral

\section{saturated $\mathrm{N}$-heterocycles}

\section{Journal Article}

Author(s):

Kreituss, Imants; Bode, Jeffrey W.

Publication date:

2017-05

Permanent link:

https://doi.org/10.3929/ethz-b-000260416

Rights / license:

In Copyright - Non-Commercial Use Permitted

Originally published in:

Nature Chemistry 9(5), https://doi.org/10.1038/nchem.2681

Funding acknowledgement:

306793 - Catalytic asymmetric synthesis of amines and amides (EC) 


\title{
Flow chemistry and polymer-supported pseudoenantiomeric acylating agents enable parallel kinetic resolution of chiral, saturated $\mathbf{N}$-heterocycles
}

\author{
Imants Kreituss and Jeffrey W. Bode* \\ Laboratorium für Organische Chemie, Department of Chemistry and Applied Biosciences, \\ ETH-Zürich, 8093 Zürich, Switzerland \\ bode@org.chem.ethz.ch
}

\begin{abstract}
Kinetic resolution is a common method to obtain enantioenriched material from a racemic mixture. This process will always deliver enantiopure unreacted material if the reactions are allowed to proceed to sufficient conversion and the selectivity is not unity $(s>1)$. However, the scalemic reaction product often is discarded, meaning, that the yield of this process seldom exceeds $40-45 \%$. Parallel kinetic resolution can grant access to two distinct, highly enantioenriched products from a single racemic starting material. Here we describe the development of a flow-based system that enables practical parallel kinetic resolution (PKR) of a broad range of racemic saturated $\mathrm{N}$-heterocycles. This process provides access to both enantiomers of the racemic starting material in good yield and high enantiopurity; similar results with classical kinetic resolution would require selectivities in the range of $s=100$. To achieve this, two immobilized quasienantiomeric acylating agents were designed for the asymmetric acylation of racemic saturated N-heterocycles. Using the flow-based system we could efficiently separate, recover and reuse the polymer-supported reagents. The amide products were obtained in good yields and high enantiopurities and could be readily separated and hydrolyzed to the corresponding amines without detectable epimerization.
\end{abstract}


Kinetic resolution (KR) is a widely used method to separate one enantiomer of a chiral compound from a racemic mixture. ${ }^{1,2}$ This occurs by selective chemical transformation of one enantiomer to a new product, which is typically formed with only modest enantiomeric excess. Unless reagents, such as enzymes, with selectivity factors $(s)>500$ are used, kinetic resolution is useful for producing the enantioenriched starting material with excellent enantiopurity and modest yields, but is typically not appropriate if both enantiomers are needed in high enantiopurity as the product enantiopurity is modest. ${ }^{3}$ Parallel kinetic resolution - in which both enantiomers of the starting material undergo reactions with pseudoenantomeric reagents - can lead to distinct products, each with high enantiomeric excess. So far this strategy has been difficult to implement in a practical fashion due to challenge of physically separating the reagents and readily isolating the pseudoenantiomeric products. ${ }^{4}$ In this report, we describe the combination of flow chemistry, solid supported resolving agents, and readily cleavable tertiary amides for the successful parallel kinetic resolution of chiral, saturated N-heterocycles including piperazines, morpholines, piperdines, tetrahydroisoquinolines, and others. Despite an intrinsic selectivity of only $s=10-20$ in most cases, flow-based parallel kinetic resolution allows the two enantiomers to be isolated in good yield and outstanding enantiomeric excesses, an outcome that would normally require reagents with selectivities in the range of $s=50-$ 100.

In a typical kinetic resolution the enantioenriched starting material is recovered at the expense of enantiopurity of the product by running the reaction to higher conversion; the scalemic product is often discarded. Although kinetic resolution can in principle provide the recovered starting material in high enantiopurity, in practice it is often difficult and time consuming to run the reactions to sufficient conversion. To increase the efficiency of the resolution, maximize the enantiopurity of the product and gain access to both enantiomers of the racemate, Vedejs introduced the concept of parallel kinetic resolution (PKR). ${ }^{5}$ In PKR, two kinetic resolution reactions are conducted simultaneously to yield two distinct non-enantiomeric products (Fig. 1a). If both enantiomers of the racemate react with similar rates, the optimal 1:1 enantiomer concentration is maintained throughout the course of the resolution and both products are formed in significantly improved enantiopurity as compared to a classical 
kinetic resolution (Fig. 1b). For a successful PKR, the implemented resolution reactions should: a) have similar (preferably identical) rates $\mathrm{k}_{R} \approx \mathrm{k}_{S} ; \mathrm{b}$ ) occur without mutual interference; c) have opposite enantioselectivity with respect to the substrate; d) yield separable reaction products. ${ }^{6}$ Due to these requirements the reaction design of PKR is difficult; while several conceptual examples of PKR have been reported, very few practical implementations have emerged. ${ }^{7-9}$ Enantiodivergence can also be achieved using a single chiral reagent or catalyst, most often leading to enantioenriched regioisomeric ${ }^{10-15}$ or diastereomeric ${ }^{16-18}$ products. Such processes are referred to as regiodivergent or stereodivergent reactions of racemic mixtures and they are more common in organic synthesis. ${ }^{4}$ These are attractive processes when they can be implemented, however they do not fully benefit from the inherent advantages of a true parallel kinetic resolution. ${ }^{19}$

We have recently reported immobilized chiral acyl hydroxamic acid (PEARL - polymeric reagents for kinetic resolution) for the kinetic resolution of saturated N-heterocycles on both small $(100 \mathrm{mg})$ and preparative $(>20 \mathrm{~g})$ scale (Fig. 1c). ${ }^{20}$ Using the PEARL reagents, we could obtain enantiopure amines from their racemates, albeit in diminished yields at the expense of the scalemic product. As both enantiomers of the PEARL reagents are readily available on scale, we sought to tackle the resolution of saturated N-heterocycles via parallel kinetic resolution. Herein, we report successful application of polymer bound quasienantiomeric reagents for the PKR of a broad range of chiral Nheterocycles. To achieve the essential physical separation of the PEARL reagents, while still allowing for near simultaneous reaction times and facile regeneration, we developed a flow-based implementation of this chemistry. We further developed acyl groups that allow for facile separation of the enantioenriched amide products and subsequent deprotection in good yields without epimerization, resulting in an overall kinetic resolution of the enantiomeric N-heterocycles with selectivities and yields far exceeding that possible with traditional approaches (Fig 1d). 


\section{Results}

Selection of Orthogonal, Cleavable Acyl Groups. To prepare the quasienantiomeric resolving agents necessary for the parallel kinetic resolution, we first set out to identify two orthogonal acyl groups that would meet strict requirements. They should be inexpensive, easy to prepare, exhibit good selectivity, react with similar rates (i.e. provide similar selectivity in classical kinetic resolution), and afford separable products. Carbonate and carbamate derivatives $\mathbf{1 a}$ and $\mathbf{1 b}$ - as well as acetate $\mathbf{1} \mathbf{c}-$ did not afford any selectivity, and hydrocinnamoyl group 1d proved very difficult to hydrolyze. After screening multiple variants, we identified the pent-4-enoyl 1e and 3-(2-nitrophenyl)propanoyl 1f groups, which afforded reasonable selectivities in the kinetic resolution and could be cleaved from the amide product (Fig. 2). The requisite pent-4-enoic acid is commercially available and inexpensive; 3-(2-nitrophenyl)propanoic acid was prepared in two steps on a decagram scale (Supplementary page 10).

Parallel Kinetic Resolution with Mixed Beads. To test if the polymeric reagents could be applied for parallel kinetic resolution, we combined the quasienantiomeric acylating agents in an equimolar ratio in THF and treated the mixture with racemic amines. After $24 \mathrm{~h}$ at $45^{\circ} \mathrm{C}$ the resulting amide products were isolated in good yields and high enantiopurity. The enantiomeric ratio of the amides was independent of the amount of the polymer used in the process, indicating that the resolution proceeds without interactions between the acylating reagents. A broad range of cyclic secondary amines were evaluated and all products were obtained with useful enantiomeric ratios. To obtain similar results in classical kinetic resolution of cyclic secondary amines very high selectivities would be required ( $s$ up to 90), which so far have been unprecedented in amine resolution with small molecule resolving agents (Table 1).

Batch Reactors for Recovery of PEARL Reagents. Previously, we demonstrated that the PEARL reagents could be readily recovered, recycled by treatment with the corresponding acid anhydride and reused in kinetic resolution without erosion in reactivity or selectivity. We have established that a single batch can be used and regenerated dozens of time for different substrates without loss of activity. However, for parallel kinetic resolution experiments the two resins were mixed together and were not recoverable after the reaction. In order to recycle the acylating agents after the reaction and render the process practical, we 
designed an H-tube reactor with two compartments. The polymeric reagents were separated with a Teflon membrane, which was permeable to the solution of the amine (Table 2). To maintain the requisite $45^{\circ} \mathrm{C}$ reaction temperature the H-tube reactor was placed on a shaker in a heated oven. Such experimental setup allowed us to run the reactions on a more convenient $(1.0-2.0 \mathrm{mmol})$ scale and recover the PEARL reagents after each reaction. The amide products were obtained in good yields albeit with diminished enantiopurity, although even the best results were not reproducible. The diminished selectivity could be explained by unequal reaction mixing, insufficient swelling of the resin and other physical factors. These results were rather disappointing, as the enantiopurities were similar to those obtained by classical kinetic resolution using PEARL reagents.

Flow-enabled Parallel Kinetic Resolution. The batch reactor possessed additional shortcomings including difficult control of the reaction temperature, as well as solvent evaporation and leaking. To address these issues we turned to advances in flow chemistry as an alternative. Flow systems can offer multiple practical advantages for reaction setup and control such as - safer handling of hazardous and highly reactive intermediates, better heat and mass transfer, improved reactant residence time control, reagent and reaction chamber separation and full process automation. ${ }^{21-23}$ Flow processes have been implemented for numerous homogenous ${ }^{24-30}$ and heterogeneous ${ }^{31,32}$ reactions including asymmetric transformations using immobilized reagents or catalysts. ${ }^{33-36}$

A simple but suitable system for parallel kinetic resolution in flow was constructed from two glass columns, an HPLC pump and a column heater. The columns were charged separately with the acylating agents and sealed with a membrane to ensure that the polymer could not elute. A solution of the amine in THF was cycled through the columns at a flow rate $2-3 \mathrm{~mL} / \mathrm{min}$ for $24 \mathrm{~h}$ at $45{ }^{\circ} \mathrm{C}$. This flow rate proved optimal for good mixing between the solid and the solution phases. The rate of the mixing is much faster than the rate of the acylation allowing the amine to be in simultaneous contact with both acylating agents. After the reaction the system was flushed with THF and $\mathrm{Et}_{2} \mathrm{O}$ and the resulting amides were separated. The obtained yields and enantiopurities were in the same range or slightly higher as in the scenario where both resins were mixed together in one pot. The flow system simplified polymer recovery and reuse; the columns were disconnected and the resins separately reacylated and reused for the subsequent resolution cycle. 
Automation of the column regeneration step should be possible with more advanced flow instrumentation. The more dense columns seals prevented leakage of the polymer and the adjusted flow rate improved the mixing; column heating was easily achieved with a standard column heating block. Overall, the flow system turned out to be far more reliable and user-friendly than the batch reactors and was essential for practical resolutions (Table 3).

Amine Deprotection. With sufficient isolated quantities of the amides we proceeded to study the hydrolysis with the enantioenriched products. Amides are remarkably stable (half-life $>10^{2}$ years at room temperature at $\mathrm{pH} 7)^{37}$ and traditional conditions for hydrolysis, such as strong acids $\left(\mathrm{HCl}\right.$ or $\left.\mathrm{H}_{2} \mathrm{SO}_{4}\right)$ or strong bases $(\mathrm{NaOH}$ or $\mathrm{LiOH})$, did not afford the amine products in reasonable yields. Instead, we utilized the olefin and the nitro groups to induce an intramolecular cyclization to form a readily cleaved intermediate. The pent-4-enoyl amide could be hydrolyzed by treatment with molecular iodine in an aqueous THF mixture and the corresponding amines could be obtained in excellent yields. ${ }^{38}$ For the 3-(2-nitrophenyl)propanoyl ${ }^{39}$ derived amides the nitro group was reduced to the corresponding aniline followed by intramolecular lactamization and concomitant deprotection under acidic conditions. After screening multiple acids, we found that full conversion and good yields of the amine could be obtained simply by heating the amide in acetic acid. Importantly, the deprotection of both pent-4-enoyl and 3-(2-nitrophenyl)propanoyl amides proceeded without detectable epimerization (Table $4 \mathrm{a}$ and $4 \mathrm{~b}$ ).

In the cases when the separation of the amide products after the resolution proved difficult, such as in the case of mefloquine, a sequential hydrolysis protocol could be applied (Table 4c). The resolution reaction mixture, containing an $\sim 1: 1$ mixture of enantioenriched amides $\mathbf{2 5}$ and $\mathbf{2 6}$, was treated with molecular iodine to selectively hydrolyze the pentenoyl amide 25 . The amine product 27 was easily separated from the unreacted amide $\mathbf{2 6}$ and was isolated in high yield (90\% yield in respect to amide $\mathbf{2 5}$ ). The unreacted amide $\mathbf{2 6}$ was hydrogenated over $\mathrm{Pd} / \mathrm{C}$ and heated in $\mathrm{AcOH}$ to afford the amine $\mathbf{2 8}$ in $\mathbf{7 8 \%}$ yield. Both of these steps proceeded without detectable epimerization. This protocol proved applicable to other amide products of the parallel kinetic resolution. 


\section{Discussion}

The increasing interest in tandem and cooperative catalysis reactions, often with catalysts that must be recovered or may be mutually incompatible, demands innovative approaches to maintain separation. Current approaches include catalyst separation in different solution phases ${ }^{40}$ the use of micelles ${ }^{41,42}$ or applications of heterogeneous or immobilized catalysts. ${ }^{43}$ By performing reactions in flow, catalyst separation and regeneration is easily achieved with no detriment to the reaction yields or selectivities. As far as we are aware, this is the first example of two asymmetric reactions occurring in parallel, rather than in sequence, in a flow based system. This concept should be easily transferred to many other cases, such as the combination of enzymes and transition metals ${ }^{44-46}$ or metals and organic catalysts. ${ }^{47}$ Importantly, it should work well in cases where the product of one catalyst reaction is the substrate of the other but the catalysts are not compatible with one another. ${ }^{48,49}$

In conclusion, parallel kinetic resolution with reusable PEARL reagents allows access to both enantiomers of cyclic secondary amines in high enantiopurity. Two complimentary acyl groups have been identified alongside suitable conditions for their hydrolysis. The use of a user-friendly flow-based reaction allowed facile separation of the pseudoenantiomeric products and greatly simplifies the regeneration and reuse of the reagents. This concept should prove broadly useful in other chemical processes that benefit from physical separation of distinct reagents or catalysts.

\section{Methods}

Two separate $5 \mathrm{~mL}$ glass columns were charged with $(500 \mathrm{mg}, \sim 1.50 \mathrm{mmol} / \mathrm{g}, 0.50$ equiv) of each of the polymeric reagents. The polymers were allowed to swell by flushing the system with THF at a flow rate of 3 $\mathrm{mL} / \mathrm{min}$ at $45^{\circ} \mathrm{C}$ for $15-20 \mathrm{~min}$. The amine ( $1.5 \mathrm{mmol}, 1.00$ equiv) was flushed through the system for $18-$ $24 \mathrm{~h}$ at a flow rate of $3 \mathrm{~mL} / \mathrm{min}$ and temperature of $45^{\circ} \mathrm{C}$. After the reaction the polymers were washed with THF $(3 \times$ three column volumes $)$ and $\mathrm{Et}_{2} \mathrm{O}(2 \times$ three column volumes $)$. The amide products were separated by column chromatography and the polymers were regenerated by treatment with the corresponding acid anhydride. 


\section{Acknowledgements}

This work was supported by the European Research Council (ERC Starting Grant No. 306793-CASAA) and the Swiss Federal Commission for Technology and Innovation (CTI 15523.1). S.-Y. Hsieh, B. Wanner and K.-Y. Chen (all ETH) are thanked for helpful discussions and advice with flow-based systems.

\section{Author contributions}

J.W.B. and I.K. contributed equally to the design of the study. J.W.B. and I.K. co-wrote the paper. I.K. performed the experiments and wrote the Supplementary Information.

\section{Competing financial Interests}

The authors declare no competing financial interests. 
Figure 1. Principles of kinetic and parallel kinetic resolution. a) Theoretical background of kinetic and parallel kinetic resolution. b) Simulation of a KR and PKR reaction system (with $s=20$ ) showing the \%enantiomeric excess of the products or starting materials during the course of the reaction (For more detailed discussion regarding reaction progress simulations see Supplementary page 5 -9). In parallel kinetic resolution, the enantiopurity of the two pseudoenantiomeric products remains constant. c) Kinetic resolution with PEARL (polymeric reagents for amine resolution) reagents. Enantiopure amines can be recovered in $<40 \%$ yield; scalemic amide product is discarded; selectivity in the range $s=10-20$; delivers non cleavable acyl groups. d) Flow enabled parallel kinetic resolution. Simple reaction setup; cleavable acyl groups; $s$ - up to 100 ; both amines recovered in high er.

Figure 2. Acylating agents and $s$ factors afforded in kinetic resolution. Enantiomeric ratios of the unreacted starting material and product were determined by supercritical fluid chromatography (SFC) or high performance liquid chromatography (HPLC) on chiral stationary phases. $s$ - selectivity factor was calculated according to Ref. 2. 
Table 1. Parallel kinetic resolution of saturated N-heterocycles.

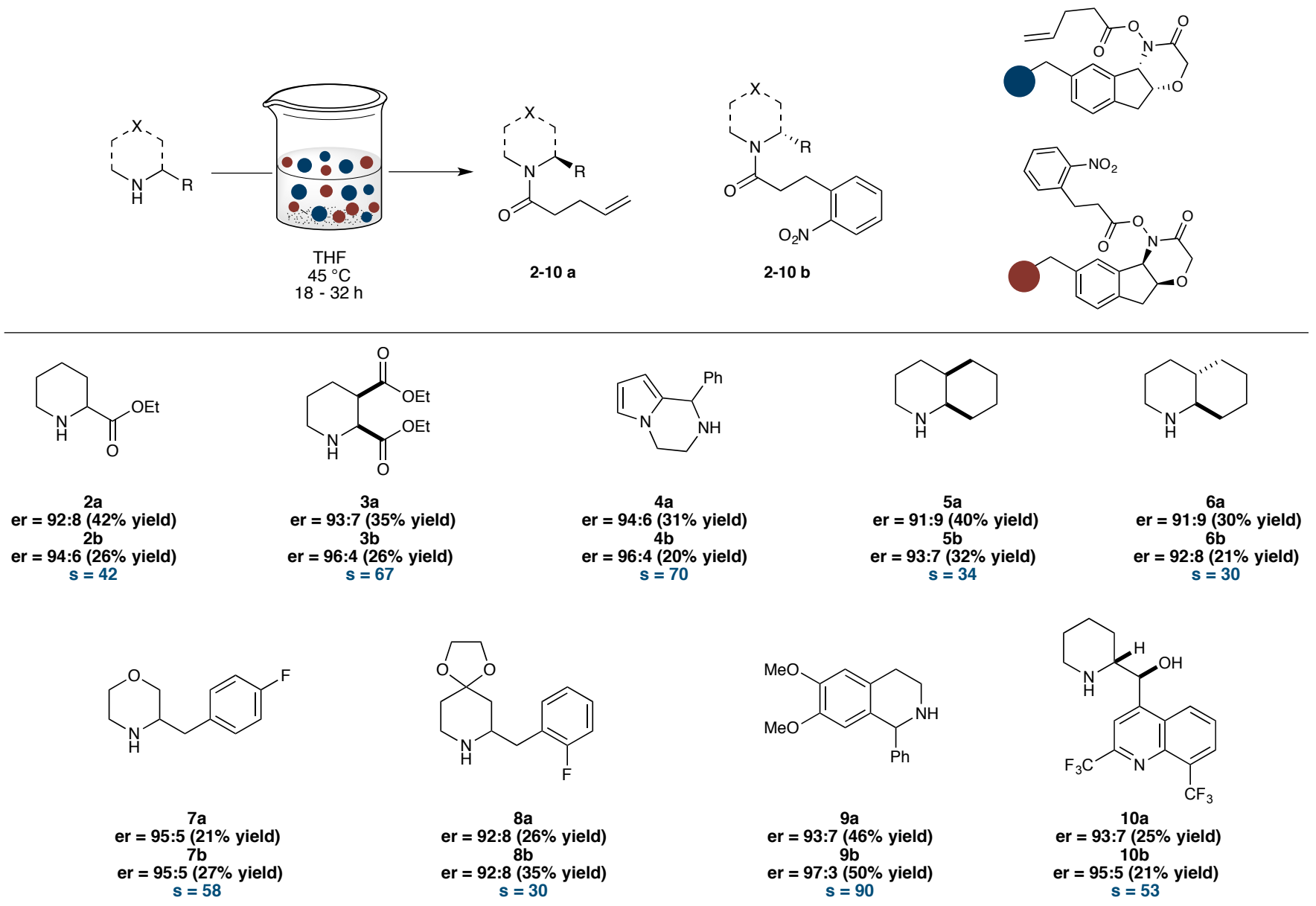

Reactions were carried out on a $0.4 \mathrm{mmol}$ scale in THF at $45{ }^{\circ} \mathrm{C}$ for $18-32 \mathrm{~h}$ using equimolar ratios of the immobilized acylating agents and racemic amine. Yields correspond to isolated products purified by column chromatography. Enantiomeric ratios were determined by SFC or HPLC on chiral stationary phases. $s-$ selectivity factor required to obtain given enantiopurities under classical kinetic resolution conditions. 


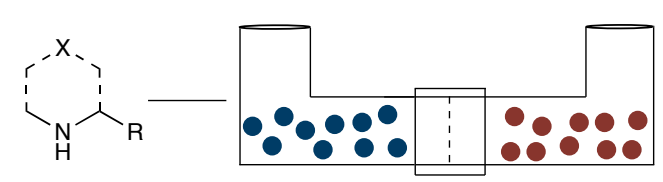

THF, $45^{\circ} \mathrm{C}$ shaker in an oven

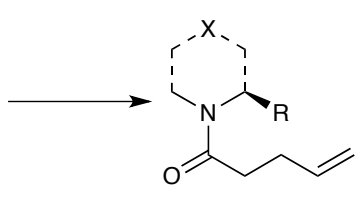

$2,6,7,11,12 a$

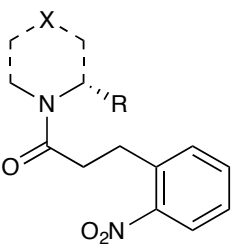

$2,6,7,11,12 b$

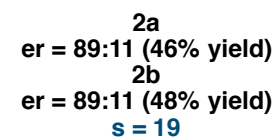<smiles>C1CC[C@H]2CCCNC2C1</smiles><smiles>Fc1ccc(CC2COCCN2)cc1</smiles>
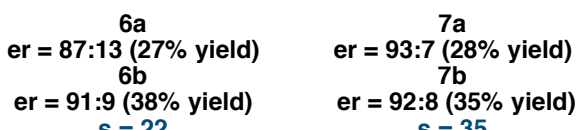
$11 \mathrm{a}$ er $=84: 16$
$11 \mathrm{~b}$ er $=91: 9$ $s=20$
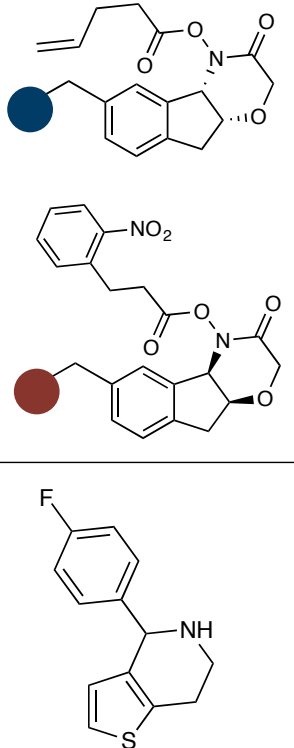

$12 a$ er $=86: 14(37 \%$ yield $)$ er $=90: 10(50 \%$ yield $)$ $s=19$

Reactions were carried out on a $1.0-2.0 \mathrm{mmol}$ scale in THF at $45^{\circ} \mathrm{C}$ for $24 \mathrm{~h}$ using equimolar ratios of the immobilized acylating agents and the racemic amine. The acylating agents were separated by a Teflon membrane mesh and the $\mathrm{H}$-tube reactor was placed on a shaker in an oven to maintain reaction temperature and mixing. Yields correspond to products purified by column chromatography. Enantiomeric ratios were determined by SFC or HPLC on chiral stationary phases. $s$ - selectivity factor required to obtain given enantiopurities under classical kinetic resolution conditions. 
Table 3. Parallel kinetic resolution in flow.

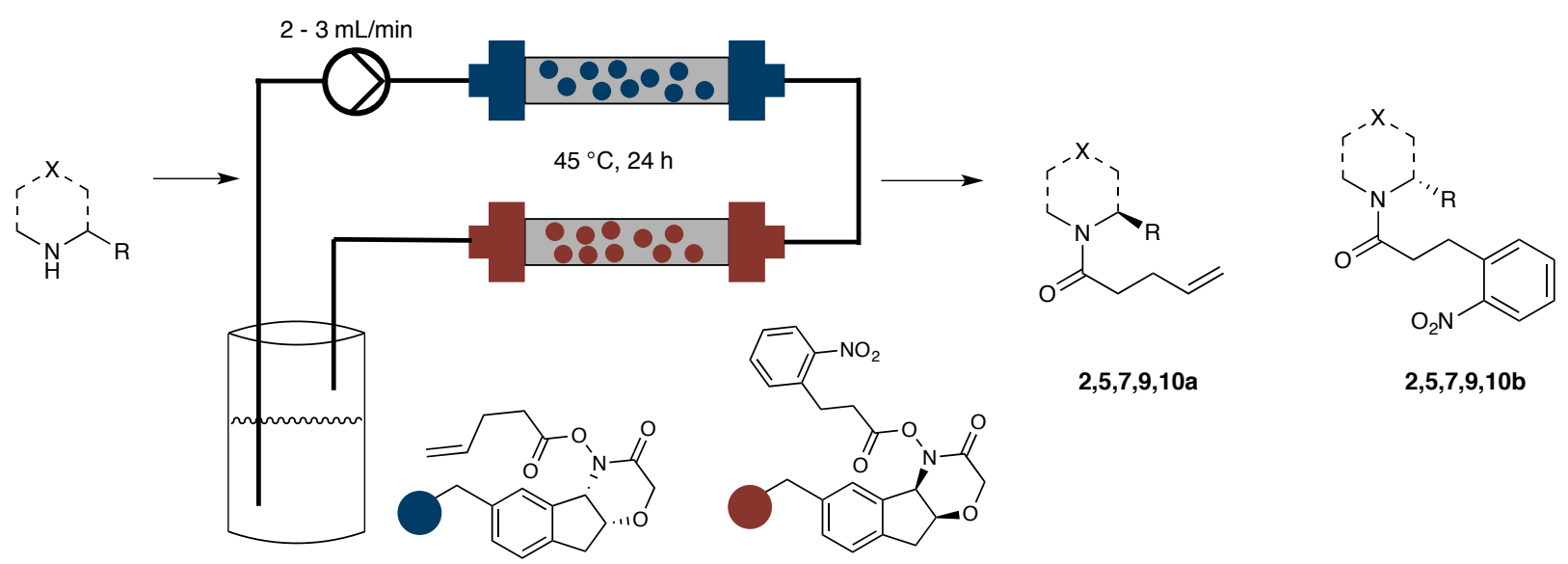<smiles>CCOC(=O)C1CCCCN1</smiles>

$2 \mathrm{a}$ er $=95: 5(50 \%$ yield $)$ $2 b$ er $=93: 7(48 \%$ yield $)$ $s=53$<smiles>C1CC[C@H]2NCCC[C@@H]2C1</smiles>

5 a er $=89: 11(45 \%$ yield $)$ $5 b$ er $=95: 5(35 \%$ yield $)$<smiles>Fc1ccc(CC2COCCN2)cc1</smiles>

$7 \mathrm{a}$ er $=96: 4(28 \%$ yield $)$ $7 \mathrm{~b}$ er $=94: 6(35 \%$ yield $)$ $s=70$<smiles>COc1cc2c(cc1OC)C(c1ccccc1)NCC2</smiles>

9a er $=97: 3(40 \%$ yield $)$ $9 b$ er $=96: 4(48 \%$ yield $)$ $\mathrm{s}=106$<smiles>O[C@H](c1cc(C(F)(F)F)nc2c(C(F)(F)F)cccc12)[C@H]1CCCCN1</smiles>

$10 \mathrm{a}$ er $=94: 6(18 \%$ yield $)$ $10 \mathrm{~b}$ er $=96: 4(17 \%$ yield $)$
$s=70$

Reactions were carried out on a $1.5 \mathrm{mmol}$ scale in THF at $45^{\circ} \mathrm{C}$ for $18-32 \mathrm{~h}$ at a flow rate of $2-3 \mathrm{~mL} / \mathrm{min}$ using $2 \times 5 \mathrm{~mL}$ glass columns. Equimolar ratios of the immobilized acylating agents $(500 \mathrm{mg}, 1.5 \mathrm{mmol} / \mathrm{g})$ and racemic amine $(1.5 \mathrm{mmol})$ were used. Yields correspond to isolated products purified by column chromatography. Enantiomeric ratios were determined by SFC or HPLC on chiral stationary phases. $s-$ selectivity factor required to obtain given enantiopurities under classical kinetic resolution conditions. 
Table 4. Amide product hydrolysis.

a)
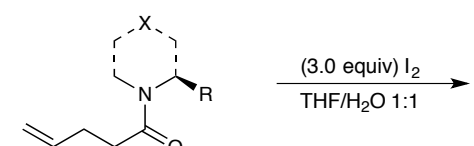

13 a-e

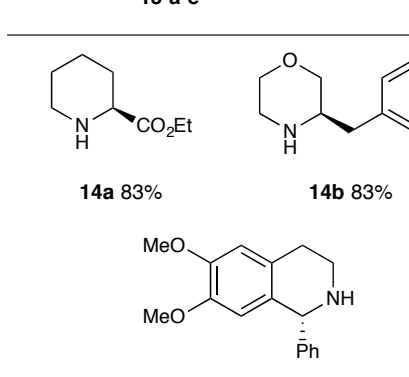

14d $89 \%$

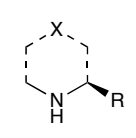

14 a-e
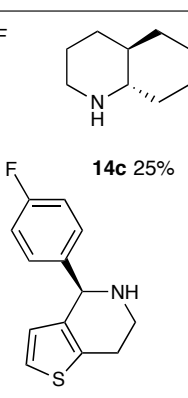

$14 \mathrm{e} 80 \%$ b)

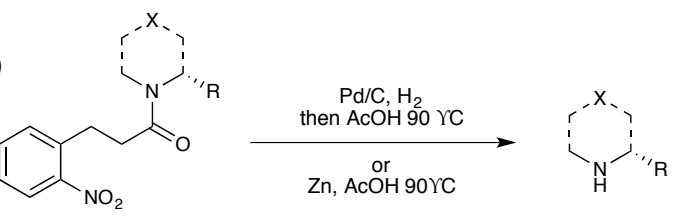

15 a-e<smiles>CCOC(=O)[C@@H]1CCCCN1</smiles>

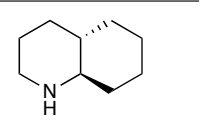

16a $77 \%$

16 b $83 \%$

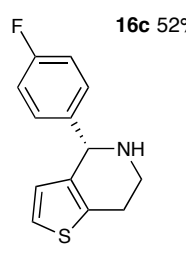

16 e $64 \%$

c)<smiles>C=CCCN1CCCC[C@H]1C(O)c1cc(C(F)(F)F)nc2c(C(F)(F)F)cccc12</smiles>

10a

e.r. 97:3<smiles>O=[N+]([O-])c1ccccc1CCCN1CCCC[C@H]1[C@H](O)c1cc(C(F)(F)F)nc2c(C(F)(F)F)cccc12</smiles>

$10 \mathrm{~b}$

e.r. 94:6
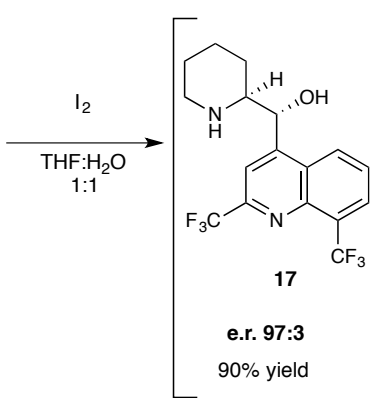<smiles>O=[N+]([O-])c1ccccc1CCCN1CCCC[C@H]1[C@H](O)c1cc(C(F)(F)F)nc2c(C(F)(F)F)cccc12</smiles>

10b

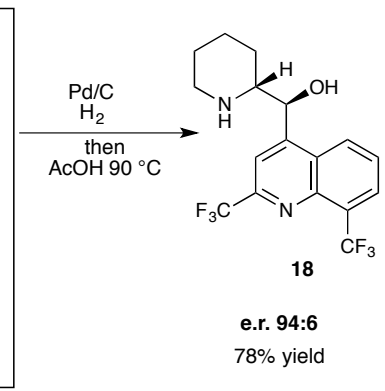

$60 \%$ yield

$78 \%$ yield

1:1 mixture of amides
difficult to separate

products easy
to separate

a) Pent-4-enoyl amides (1.0 equiv) were hydrolyzed by treatment with $\mathrm{I}_{2}$ (3.0 equiv) in a 1:1 mixture of THF: $\mathrm{H}_{2} \mathrm{O}$ for $2-8 \mathrm{~h}$. b) 3-(2-Nitrophenyl)propanoyl amides were reduced to corresponding aniline derivatives using $\mathrm{Pd} / \mathrm{C}$ and $\mathrm{H}_{2}$ or $\mathrm{Zn} / \mathrm{AcOH}$ followed by hydrolysis in $\mathrm{AcOH}$ at $90{ }^{\circ} \mathrm{C}$. Yields correspond to products purified by column chromatography. Product enantiopurity was confirmed by SFC or HPLC analysis on chiral stationary phases. c) Sequential hydrolysis protocol. The mixture of amides was first treated with $\mathrm{I}_{2}$ (3.0 equiv) in a 1:1 mixture of THF: $\mathrm{H}_{2} \mathrm{O}$. Resulting unprotected N-heterocycle and 3-(2nitrophenyl)propanoyl amide were separated and the latter was hydrolyzed using $\mathrm{Pd} / \mathrm{C}$ and $\mathrm{H}_{2}$ followed by heating in $\mathrm{AcOH}$ at $90{ }^{\circ} \mathrm{C}$. Yields correspond to products purified by column chromatography. Product enantiopurity was confirmed by SFC or HPLC analysis on chiral stationary phases. 
Page 14 of 19 


\section{References}

[1] Keith, J. M., Larrow, J. F. \& Jacobsen, E. N. Practical considerations in kinetic resolution reactions. Adv. Synth. Catal. 343, 5-26 (2001).

[2] Kagan, H. B. \& Fiaud, J.-C. Kinetic resolution. Top. Stereochem. 18, 249-330 (1988).

[3] Vedejs, E. \& Jure, M. Efficiency in nonenzymatic kinetic resolution. Angew. Chem. Int. Ed. Engl. 44, 3974-4001 (2005).

[4] Russell, T. A. \& Vedejs, E. Enantiodivergent reactions: divergent reactions on a racemic mixture and parallel kinetic resolution, in separation of enantiomers : synthetic methods (ed M. Todd), Wiley-VCH Verlag GmbH \& Co. KGaA, Weinheim, Germany. doi: 10.1002/9783527650880.ch6 (2014).

[5] Vedejs, E. \& Chen, X. Parallel kinetic resolution. J. Am. Chem. Soc. 119, 2584-2585 (1997).

[6] Dehli, J. R. \& Gotor, V. Parallel kinetic resolution of racemic mixtures: a new strategy for the preparation of enantiopure compounds? Chem. Soc. Rev 31, 365-370 (2002).

[7] Vedejs, E. \& Rozners, E. Parallel kinetic resolution under catalytic conditions : a three-phase system allows selective reagent activation using two catalysts. J. Am. Chem. Soc. 123, 2428 $2429(2001)$.

[8] Duffey, T. A., MacKay, J. A. \& Vedejs, E. Catalytic parallel kinetic resolution under homogeneous conditions. J. Org. Chem. 75, 4674-4685 (2010).

[9] Liao, L. A., Zhang, F., Dmitrenko, O., Bach, R. D. \& Fox, J. M. A Reactivity/affinity switch for parallel kinetic resolution: $\alpha$-amino acid quasienantiomers and the resolution of cyclopropene carboxylic acids. J. Am. Chem. Soc. 126, 4490-4491 (2004).

[10] Kamlet, A. S., Préville, C., Farley, K. A. \& Piotrowski, D. W. Regioselective hydroarylations and parallel kinetic resolution of Vince lactam. Angew. Chem. Int. Ed. 52, 10607-10610 (2013).

[11] Wu, B., Parquette, J. R. \& RajanBabu, T. V. Regiodivergent ring opening of chiral aziridines. Science 326, 1662 (2009). 
[12] Langlois, J. B. \& Alexakis, A. Identification of a valuable kinetic process in copper-catalyzed asymmetric allylic alkylation. Angew. Chem. Int. Ed. 50, 1877-1881 (2011).

[13] Bertozzi, F., Crotti, P., Macchia, F., Pineschi, M. \& Feringa, B. Highly enantioselective regiodivergent and catalytic parallel kinetic resolution. Angew. Chem. Int. Ed. 40, 930-932 (2001).

[14] Tanaka, K. \& Fu, G. C. Parallel kinetic resolution of 4-alkynals catalyzed by $\mathrm{Rh}(\mathrm{I}) / \mathrm{Tol}-$ BINAP: Synthesis of enantioenriched cyclobutanones and cyclopentenones. J. Am. Chem. Soc. 125, 8078-8079 (2003).

[15] Webster, R., Böing, C. \& Lautens, M. Reagent-controlled regiodivergent resolution of unsymmetrical oxabicyclic alkenes using a cationic rhodium catalyst. J. Am. Chem. Soc. 131, 444-445 (2009).

[16] Chavez, D. E. \& Jacobsen, E. N. Catalyst-controlled inverse-electron-demand hetero-DielsAlder reactions in the enantio- and diastereoselective synthesis of iridoid natural products. Org. Lett. 5, 2563-2565 (2003).

[17] Dehli, J. R. \& Gotor, V. Preparation of enantiopure ketones and alcohols containing a quaternary stereocenter through parallel kinetic resolution of $\beta$-keto nitriles. J. Org. Chem. 67, 1716-1718 (2002).

[18] Abril, O. \& Whitesides, G. M. Hybrid organometallic/enzymic catalyst systems: regeneration of NADH using dihydrogen. J. Am. Chem. Soc. 104, 1552-1554 (1982).

[19] Doyle, M. P. et al. Highly selective enantiomer differentiation in intramolecular cyclopropanation reactions of racemic secondary allylic diazoacetates. J. Am. Chem. Soc. 117, 11021-11022 (1995).

[20] Kreituss, I. et. al. Robust, recyclable resin for decagram scale resolution of ( \pm )-mefloquine and other chiral N-heterocycles. Angew. Chem. Int. Ed. 55, 1553-1556 (2015).

[21] Pastre, J. C., Browne, D. L. \& Ley, S. V. Flow chemistry syntheses of natural products. Chem. Soc. Rev. 42, 8849-8869 (2013).

[22] Atodiresei, I., Vila, C. \& Rueping, M. Asymmetric organocatalysis in continuous flow: Opportunities for impacting industrial catalysis. ACS Catal. 5, 1972-1985 (2015). 
[23] Webb, D. \& Jamison, T. F. Continuous flow multi-step organic synthesis. Chem. Sci. 1, 675680 (2010).

[24] Snead, D. R. \& Jamison, T. F. A three-minute synthesis and purification of ibuprofen: Pushing the limits of continuous-flow processing. Angew. Chem. Int. Ed. 54, 983-987 (2015).

[25] Battilocchio, C. et. al. Iterative reactions of transient boronic acids enable sequential C - C bond formation. Nat. Chem. 8, 360 - 367 (2016).

[26] Adamo, A. et. al. On-demand continuous-flow production of pharmaceuticals in a compact, reconfigurable system. Science, 352, 61-67 (2016).

[27] Chen, M. \& Buchwald, S. L. Rapid and efficient trifluoromethylation of aromatic and heteroaromatic compounds using potassium trifluoroacetate enabled by a flow system. Angew. Chem. Int. Ed. 52, 11628-11631 (2013).

[28] Shu, W. \& Buchwald, S. L. Enantioselective $\beta$-arylation of ketones enabled by lithiation/borylation/1,4-addition sequence under flow conditions. Angew. Chem. Int. Ed. 51, 5355-5358 (2012).

[29] Ganiek, M. A., Becker, M. R., Ketels, M. \& Knochel, P. Continuous flow magnesiation or zincation of acrylonitriles, acrylates, and nitroolefins. Application to the synthesis of butenolides. Org. Lett. 18, 828-831 (2016).

[30] Mallia, C. J. \& Baxendale, I. R. The use of gases in flow synthesis. Org. Process Res. Dev. 20, 327-360 (2015).

[31] Dong, K., Sun, C. H., Song, J. W., Wei, G. X. \& Pang, S. P. Synthesis of 2,6,8,12-tetraacetyl2,4,6,8,10,12-hexaazaisowurtzitane (TAIW) from 2,6,8,12-tetraacetyl-4,10-dibenzyl$2,4,6,8,10,12$ - hexaazaisowurtzitane (TADBIW) by catalytic hydrogenolysis using a continuous flow process. Org. Process Res. Dev. 18, 1321-1325 (2014).

[32] Baxendale, I. R., Ley, S. V., Mansfield, A. C. \& Smith, C. D. Multistep synthesis using modular flow reactors: Bestmann-Ohira reagent for the formation of alkynes and triazoles. Angew. Chem. Int. Ed. 48, 4017-4021 (2009).

[33] Annis, D. A. \& Jacobsen, E. N. Polymer-supported chiral Co (Salen) complexes : synthetic applications and mechanistic investigations in the hydrolytic kinetic resolution of terminal epoxides. J. Am. Chem. Soc. 121, 4147-4154 (1999). 
[34] Adint, T. T. \& Landis, C. R. Immobilized bisdiazaphospholane catalysts for asymmetric hydroformylation. J. Am. Chem. Soc. 136, 7943-7953 (2014).

[35] Kamahori, K., Ito, K. \& Itsuno, S. Asymmetric Diels-Alder reaction of methacrolein with cyclopentadiene using polymer-supported catalysts: design of highly enantioselective polymeric catalysts. J. Org. Chem. 61, 8321-8324 (1996).

[36] Csajagi, C. et al. Enantiomer selective acylation of racemic alcohols by lipases in continuousflow bioreactors. Tetrahedron Asymmetry 19, 237-246 (2008).

[37] Hutchby, M. et. al. Switching pathways: Room-temperature neutral solvolysis and substitution of amides. Angew. Chem. Int. Ed. 51, 548-551 (2012).

[38] Debenham, J.S.; Madsen, R.; Roberts, C. \& Fraser-Reid, B. Two new orthogonal amineprotecting groups that can be cleaved under mild or neutral conditions. J. Am. Chem. Soc. 117, 3302-3303 (1995).

[39] Entwistle, I. D. The use of 2-nitrophenylpropionic acid as a protecting group for amino and hydroxyl functions to be recovered by hydrogen transfer hydrogenation. Tetrahedron Lett. 6 , $555-558$ (1979).

[40] Shirakawa, S. \& Maruoka, K. Recent developments in asymmetric phase-transfer reactions. Angew. Chem. Int. Ed. 52, 4312-4348 (2013).

[41] Isley, N. A., Linstadt, R. T. H., Kelly, S. M., Gallou, F. \& Lipshutz, B. H. Nucleophilic aromatic substitution reactions in water enabled by micellar catalysis. Org. Lett. 17, 4734-4737 (2015).

[42] La Sorella, G., Strukul, G. \& Scarso, A. Recent advances in catalysis in micellar media. Green Chem. 17, 644-683 (2015).

[43] Kobayashi, S. Flow 'Fine' Synthesis: High yielding and selective organic synthesis by flow methods. Chem. - An Asian J. 11, 425-436 (2016).

[44] Hyster, T. K., Knorr, L., Ward, T. R. \& Rovis, T. Biotinylated Rh (III) complexes in asymmetric C-H activation. Science 338, 500-503 (2012).

[45] Paetzold, J. \& Bäckvall, J. E. Chemoenzymatic dynamic kinetic resolution of primary amines. J. Am. Chem. Soc. 127, 17620-17621 (2005). 
[46] Denard, C. A. et. al. Development of a one-pot tandem reaction combining rutheniumcatalyzed alkene metathesis and enantioselective enzymatic oxidation to produce aryl epoxides. ACS Catal. 5, 3817-3822 (2015).

[47] Allen, A. E. \& MacMillan, D. W. C. Synergistic catalysis: A powerful synthetic strategy for new reaction development. Chem. Sci. 3, 633-658 (2012).

[48] Hafez, A. M., Taggi, A. E., Dudding, T. \& Lectka, T. Asymmetric catalysis on sequentiallylinked columns. J. Am. Chem. Soc. 123, 10853-10859 (2001).

[49] Hafez, A. M., Taggi, A. E., \& Lectka, T. Column asymmetric catalysis. Chem. Eur. J. 8, 41144119 (2002). 